Available online on 15.11.2020 at http://jddtonline.info
Open Access to Pharmaceutical and Medical Research
und $2011-18$, publisher and licensee JDDT, This is an Open Access article which permits

Open 1 Access

Research Article

\title{
Ameliorative efficacy of novel multi herbal formulation (AKSS16-LIV01) upon Haematological modulations induced by fixed dose combination of tramadol hydrochloride/paracetamol (THP)
}

\author{
Soumendra Darbar ${ }^{1,2}$, Srimoyee Saha ${ }^{3}$, Kausikisankar Pramanik ${ }^{2}$ and Atiskumar Chattopadhyay ${ }^{*}$ \\ ${ }^{1}$ Faculty of Science, Jadavpur University, 188, Raja S C Mallick Road, Kolkata-700032, West Bengal, India \\ ${ }^{2}$ Department of Chemistry, Jadavpur University, 188, Raja S C Mallick Road, Kolkata-700032, West Bengal, India \\ ${ }^{3}$ Department of Physics, Jadavpur University, 188, Raja S C Mallick Road, Kolkata-700032, West Bengal, India
}

\begin{abstract}
Background: Tramadol hydrochloride/paracetamol (THP) a fixed dose combination (FDC) is widely spread analgesic used to treat moderate to moderately severe pain. Over dose or chronic use of this fixed dose combination produce serious adverse effects. An acute Tramadol hydrochloride/paracetamol (THP) overdose can lead to a fatal liver damage.

Objectives: There is a worldwide need to develop a safe and symptomatic medication which controls the different medical complications.

Materials and Methods: Healthy adult swiss albino mice were assigned to four groups of six mice each according to their weights. Group-I serve as control, Group-II received Multi herbal formulation (AKSS16 LIV01) $400 \mathrm{mg} / \mathrm{kg} / \mathrm{day}$, Group-III received Tramadol hydrochloride/paracetamol (THP) $1.68 \mathrm{~g} / 300 \mathrm{ml}$ water and Group-IV received THP along with AKSS16-LIV01 (400 mg/kg). Blood samples were collected from the retro orbital plexus of each animal to determine various blood parameters and liver transaminase. Results: Administration of THP showed decline body weight, food consumption and water intake in mice whereas treatment with Multi herbal formulation (AKSS16-LIV01) normalized the same as compared with untreated animals. Treatment with THP (Group-III) decline the packed cell volume (PCV), haempglobin ( $\mathrm{Hb})$, means cell volume (MCV), means cell hemoglobin $(\mathrm{MCH})$ and greater the white blood cell (WBC) compared with control. Pre-treatment with AKSS16-LIV01 significantly $(\mathrm{p}<0.001)$ increased the PCV, $\mathrm{Hb}, \mathrm{MCH}, \mathrm{MCH}$ and decreased WBC count in experimental animals. On the other hand elevated liver transaminase enzymes i.e. AST and ALP by THP was restored with administration of Multi herbal formulation (AKSS16-LIV01).
\end{abstract}

Conclusion: Chronic administration of THP indicated adverse effects on haematologic parameters upon experimental animals. Simultane ous administration with newly developed multi herbal formulation (AKSS16-LIV01) was ameliorate these adverse effects and may be potent drug In the future which controls the blood related medical complications against the toxicants.

Keywords: Tramadol hydrochloride/paracetamol; Fixed dose combination; Multi herbal formulation; Hematologic parameters; Liver transaminase; Swiss albino mice

Article Info: Received 27 Aug 2020; $\quad$ Review Completed 12 Oct 2020; $\quad$ Accepted 18 Oct 2020; Available online 15 Nov 2020

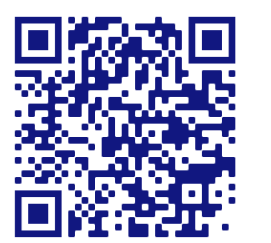

Cite this article as:

Darbar S, Saha S, Pramanik K, Chattopadhyay A, Ameliorative efficacy of novel multi herbal formulation (AKSS16-LIV01) upon Haematological modulations induced by fixed dose combination of tramadol hydrochloride/paracetamol (THP), Journal of Drug Delivery and Therapeutics. 2020; 10(6):11-17 http://dx.doi.org/10.22270/jddt.v10i6.4516

*Address for Correspondence:

Dr. Atiskumar Chattopadhyay, Ph.D, FIC, Principal Secretary, Faculty Council of Science, Jadavpur University, 188, Raja S C Mallick Road, Kolkata-700032, West Bengal, India

\section{INTRODUCTION}

Tramadol hydrochloride/paracetamol is a fixed dose combination (FDC) used to treat moderate to moderately severe pain. This fixed dose combination (FDC) contains 37.5 mg of tramadol hydrochloride and $325 \mathrm{mg}$ of paracetamol 1. Immediate release (IR) formulation orally relief pain within an hour. Tramadol has a central acting mechanism via serotonin receptors and acts by binding $\mu$-opioid receptors and neurons, and it is also a serotonin-norepinephrine reuptake inhibitor (SNRI) 2. Over dose and chronic consumption of this combination produce constipation, itchiness and nausea ${ }^{3}$. Some times more serious adverse 
effects like insomnia, drug dependency and a high risk of serotonin syndrome may occur ${ }^{4}$.

Intake of low dose of tramadol hydrochloride/paracetamol can acts as an effective analgesic but at high dosage and over a prolonged period the combination may cause various complications and disrupt body's homeostasis 5, 6. Recent study showed that application of tramadol hydrochloride/paracetamol (THP) alters normal value of the various haematological parameters in animals 7 . Apart from this prolonged or chronic administration of THP may cause severe thrombocytopenia, leading to failure of the immune system, anemia and a very low erythrocyte count 8,9 .

Multi herbal formulations mean a dosage form consisting of one or more herbs or processed herbs in specified quantities which have potent therapeutic efficacy without adverse effects 10,11. Scientific study revealed that this plant based formulation is very effective to cure anaemia and control the blood 12. Here we developed a multi herbal formulation (AKSS16-LIV01) based on six Indian medicinal plants and three Indian spices. Our previous study established that the formulation is completely safe in various does upon experimental animals 13 . With view of the above, there is need to developed and safe and symptomatic medication that controls all haematological parameters in the body when system exposed with fixed dose combination.

\section{MATERIALS AND METHODS}

\section{Chemicals}

Tramadol hydrochloride and paracetamol were obtained from Dey's Medical Stores (Mfg.) Ltd., Kolkata as a gift sample. Ethanol, sodium chloride, sodium hydroxide and TRIS buffer were obtained from Merck, India. PBS pH 7.4 was procured from Sigma-Aldrich. Biochemical determination kits i.e. ALT and AST were procured from Thermo Scientific, USA. All others reagents used in this study are laboratory grade.

\section{Preparation of plant extract}

All the medicinal plant and spice ingredients were collected from registered local herbal suppliers and authenticated by pharmacognosist. Plants parts were cleaned and dry with normal temperature. The dried plant parts were used for preparation of multi herbal formulation as per standard validated protocol 14 . The plants and plant parts used in preparation of the extract are listed in Table 1.

Table 1: Details of ingredient(s) present in the newly developed multi herbal formulation (AKSS16-LIV01)

\begin{tabular}{|c|c|c|c|}
\hline Sl. No. & Botanical Name & Common Name & Quantity used in extract \\
\hline \multicolumn{4}{|c|}{ Indian Medicinal Herbs } \\
\hline 1. & Tinospora cordifolia & Guduchi & $20 \mathrm{mg}$ \\
\hline 2. & Terminalia chebula & Haritaki & $20 \mathrm{mg}$ \\
\hline 3. & Azadirachta indica & Neem & $50 \mathrm{mg}$ \\
\hline 4. & Andrographis paniculata & Kalmegh & $50 \mathrm{mg}$ \\
\hline 5. & Aloe barbadensis miller & Aloe vera & $50 \mathrm{mg}$ \\
\hline 6. & Curcuma longa & Curcuma, Haldi & $20 \mathrm{mg}$ \\
\hline \multicolumn{4}{|c|}{ Indian Medicinal Spices } \\
\hline 7. & Trigonella foenum-graecum & Methi & $10 \mathrm{mg}$ \\
\hline 8. & Piper nigrum & Black pepper & $10 \mathrm{mg}$ \\
\hline 9. & Elettaria cardamomum & Cardamom & $10 \mathrm{mg}$ \\
\hline
\end{tabular}

* Amount required for preparation of $5 \mathrm{ml}$ extract.

\section{Animals}

Twenty four young, healthy Swiss albino mice weighing $25 \mathrm{~g}$ $\pm 5 \mathrm{~g}$ have been randomly included for the study. The animals have been housed in healthy atmospheric conditions $(12 \mathrm{~h}$ light and dark cycles, at $25 \pm 2{ }^{\circ} \mathrm{C}$ and $50-60 \%$ humidity), normal feeding, drinking, and medical care based on the CPCSEA guidelines. Mice were kept under observation for one week before the onset of the experiment for acclimatization and to exclude any unsercurrent infection. The experimental procedures were approved by the Institutional Animal Ethics Committee (IAEC) (Approval No. 261/JU/s/IAEC/Pharma/2018).

\section{Experimental procedure}

The mice were randomly assigned to four major groups of six mice each according to their body weights such that each group was made up of mice within the close range of body weight. The groups are as follows: Group-I serve as control, Group-II received Multi herbal formulation (AKSS16-LIV01)
$400 \mathrm{mg} / \mathrm{kg} /$ day, Group-III received Tramadol hydrochloride/paracetamol (THP) daily at dosage of 1.68 $\mathrm{g} / 300 \mathrm{ml}$ of water and Group-IV received THP (1.68 g/300 $\mathrm{ml}$ of water) along with AKSS16-LIV01 (400 mg/kg).

\section{Body weight, food consumption and water intake}

Body weights were measured on weekly basis from the initial day to the final day of experiment to calculate body weight alteration. Feed intake was determined by measuring feed residue on weekly basis since the beginning of the experiment. Feed conversion was obtained by dividing total feed intake by body weight gain. Water intake was determined by subtracts the remaining of water found in the drinking bottle from the initial water given to the animals.

\section{Blood Collection and serum preparation}

At the end of the respective fasting period, blood was collected from each mouse by retro orbital venous puncture. $200 \mu \mathrm{L}$ of blood sample were collected into micro-centrifuge 
tubes with and without EDTA (2\%). Collected bloods were placed in slanting position at room temperature for $2 \mathrm{hrs}$. Then, they were centrifuged at $3500 \mathrm{~g}$ for $10 \mathrm{~min}$. Clear light yellow colour serum was separated and used for further analyses.

\section{Hematological Parameters}

For hematological studies, the blood was collected in heparinized tubes. Blood-cell count was done using blood smears in Sysmax-K1000 Cell Counter. Parameters studied were hemoglobin, total red blood cell, reticulocyte, hematocrit, packed cell volume (PCV), mean corpuscular volume (MCV), mean corpuscular hemoglobin (MCH), mean corpuscular hemoglobin concentration (MCHC), platelets, total white blood cell and differential count.

\section{Determination of biochemical parameters}

Liver function enzymes such as AST and ALT were used as biochemical markers for hepatotoxicity and assayed by the standard protocol.

\section{Statistical analysis}

Data are presented as mean \pm SE. Statistical analysis of the data was carried out using two way analysis of variance (ANOVA) followed by Tukey's Multiple Comparison Test. Statistical significance was acceptable to a level of $\mathrm{p}<0.05$.

\section{RESULTS}

Effect of multi herbal formulation (AKSS16-LIV01) on Body weight, Food Consumption and Water Intake

Gross body weights and relative changes, food consumption and water intake was presented in table 2. Administration of Tramadol hydrochloride/paracetamol (THP) significantly reduced $(\mathrm{p}<0.001)$ the body weight, food intake and water intake capacity as compared with control animals. Treatment with multi herbal formulation (AKSS16-LIV01) $400 \mathrm{mg} / \mathrm{kg} /$ day normalized the body weight, daily food intake and water intake capacity as compared with Tramadol hydrochloride/paracetamol (THP) treated animals. Administration of AKSS16-LIV01 did not show any abnormal changes as compared with control animals.

Table-2: Effect of multi herbal formulation (AKSS16-LIV01) on body weight, food consumption and water intake

\begin{tabular}{|l|c|c|c|c|}
\hline \multirow{2}{*}{ Parameters } & \multicolumn{4}{|c|}{ Groups } \\
\cline { 2 - 5 } & Control & AKSS16-LIV01 & THP & THP + AKSS16-LIV01 \\
\hline Body weight (g) Initial & $25.16 \pm 2.57$ & $25.84 \pm 2.44$ & $26.01 \pm 5.21$ & $25.11 \pm 4.85$ \\
\hline Body weight (g) Final & $36.98 \pm 2.55$ & $36.91 \pm 2.69$ & $21.22 \pm 2.61^{\#}$ & $36.67 \pm 1.47^{*}$ \\
\hline Body weight (g) gain or loss & $11.82 \pm 0.06$ & $11.07 \pm 0.04$ & $4.79 \pm 0.006$ & $11.56 \pm 0.03$ \\
\hline Food consumption (g) & $4.81 \pm 0.05$ & $4.39 \pm 0.07$ & $2.97 \pm 0.05^{\#}$ & $5.18 \pm 0.04^{*}$ \\
\hline Water intake (ml) & $4.18 \pm 0.04$ & $4.27 \pm 0.04$ & $2.98 \pm 0.02^{\#}$ & $4.55 \pm 0.04^{*}$ \\
\hline
\end{tabular}

All data were expressed as means \pm SE (n=6/group). Data comparison was performed using two way ANOVA followed by Tukey's Multiple Comparison Test. \#Significantly different from the control group at $\mathrm{p}<0.001$ and *Significantly different from (THP) group values at $\mathrm{p}<0.001$

\section{Effect of multi herbal formulation (AKSS16-LIV01) on Haematological parameters}

Haematological parameters of control and experimental groups are shown in table 3 and figure 1 to 5 . Four weeks treatment with newly developed multi herbal formulation (AKSS16-LIV01) at a dose of $400 \mathrm{mg} / \mathrm{kg} /$ day did not showed significant differences in PCV, haemoglobin (Hb), WBC, RBC, mean corpuscular haemoglobin concentration (MCHC), mean cell volume (MCV), and mean cell hemoglobin (MCH) compared with the control. Significant reduction in $\mathrm{Hb}$ $(\mathrm{p}<0.001)$, PCV $(\mathrm{p}<0.001), \operatorname{MCV}(\mathrm{p}<0.001)$, and MCH $(\mathrm{p}$ $<0.001$ ) was noticed in THP intoxicated mice when compared with the Control (Figure 1-4). The WBC count
(Figure 5) was significantly $(\mathrm{p}<0.001)$ greater in Group C compared with the control. In contrast, no significant differences were observed in RBC and MCHC between the control and Group C. Administration of multi herbal formulation (AKSS16-LIV01) along with THP significantly increased $\mathrm{Hb}(\mathrm{p}<0.001), \operatorname{PCV}(\mathrm{p}<0.001), \operatorname{MCV}(\mathrm{p}<0.001)$, and $\mathrm{MCH}(\mathrm{p}<0.001)$ when compared with the THP intoxicated animals. On the other hand WBC count was significantly reduced in Group D THP + AKSS16-LIV01 intoxicated animals. Others haematological parameters (table 3) like Read Blood corpuscle (RBC); Reticulocyte (RT); Haematocrit (HCT); Mean corpuscular haemoglobin concentration (MCHC) did not show any significant changes upon all the experimental groups.

Table-3: Effect of multi herbal formulation (AKSS16-LIV01) on haematological Parameters

\begin{tabular}{|l|c|c|c|c|}
\hline \multirow{2}{*}{ Parameters } & \multicolumn{3}{|c|}{ Groups } \\
\cline { 2 - 5 } & Control & AKSS16-LIV01 & THP & $\begin{array}{c}\text { THP + AKSS16- } \\
\text { LIV01 }\end{array}$ \\
\hline RBC (x106 $\left.\boldsymbol{\mu L}^{-1}\right)$ & $10.8 \pm 4.1$ & $10.2 \pm 5.3$ & $10.1 \pm 4.2$ & $10.6 \pm 5.1$ \\
\hline RT (\%) & $2.8 \pm 1.1$ & $2.4 \pm 1.6$ & $2.8 \pm 2.4$ & $2.9 \pm 1.6$ \\
\hline HCT (\%) & $34.8 \pm 1.3$ & $32.8 \pm 2.1$ & $32.8 \pm 2.1$ & $35.1 \pm 3.1$ \\
\hline MCHC (\%) & $41.4 \pm 7.6$ & $41.7 \pm 2.4$ & $40.4 \pm 1.4$ & $41.4 \pm 1.4$ \\
\hline Platelets $\left(\mathbf{x 1 0}^{\mathbf{3}} \boldsymbol{\mu \mathbf { L } ^ { - 1 } )}\right.$ & $6.6 \pm 2.0$ & $6.9 \pm 1.2$ & $6.3 \pm 1.2$ & $6.5 \pm 2.6$ \\
\hline
\end{tabular}

Data are expressed as mean \pm standard deviation $(\mathrm{N}=6)$

RBC: Read Blood corpuscle; RT: Reticulocyte; HCT: Haematocrit; MCHC: Mean corpuscular haemoglobin concentration; 


\section{Effect of multi herbal formulation (AKSS16-LIV01) on Biochemical parameters}

Table 4 shows the mean aspartate aminotransferase (AST) and alanine aminotransferase (ALT) levels in control and experimental groups of mice. Data indicate that THP intoxicated mice had significantly greater mean AST and ALT compared with the control $(\mathrm{p}<0.001)$. Pre-treatment with multi herbal formulation (AKSS16-LIV01) at a dose of 400 $\mathrm{mg} / \mathrm{kg} /$ day normalized the elevated AST and ALT levels when compared with THP treated mice. Four weeks treatment with newly developed multi herbal formulation (AKSS16-LIV01) at a dose of $400 \mathrm{mg} / \mathrm{kg} /$ day alone did not shows significant differences in AST and ALT when compared with control group.

Table-4: Effect of multi herbal formulation (AKSS16-LIV01) on serum biochemical parameters

\begin{tabular}{|l|c|c|}
\hline Groups & AST (Unit/L) & ALT (Unit/L) \\
\hline Control & $55.28 \pm 6.34$ & $26.82 \pm 4.11$ \\
\hline AKSS16-LIV01 & $54.91 \pm 5.81$ & $27.54 \pm 4.62$ \\
\hline THP & $106.28 \pm 8.17^{\#}$ & $67.59 \pm 6.01^{\#}$ \\
\hline THP + AKSS16-LIV01 & $62.99 \pm 5.44^{*}$ & $31.83 \pm 5.18^{*}$ \\
\hline
\end{tabular}

All data were expressed as means \pm SE ( $n=6$ /group). Data comparison was performed using two way ANOVA followed by Tukey's Multiple Comparison Test. \#Significantly different from the control group at $\mathrm{p}<0.001$ and *Significantly different from (THP) group values at $\mathrm{p}<0.001$

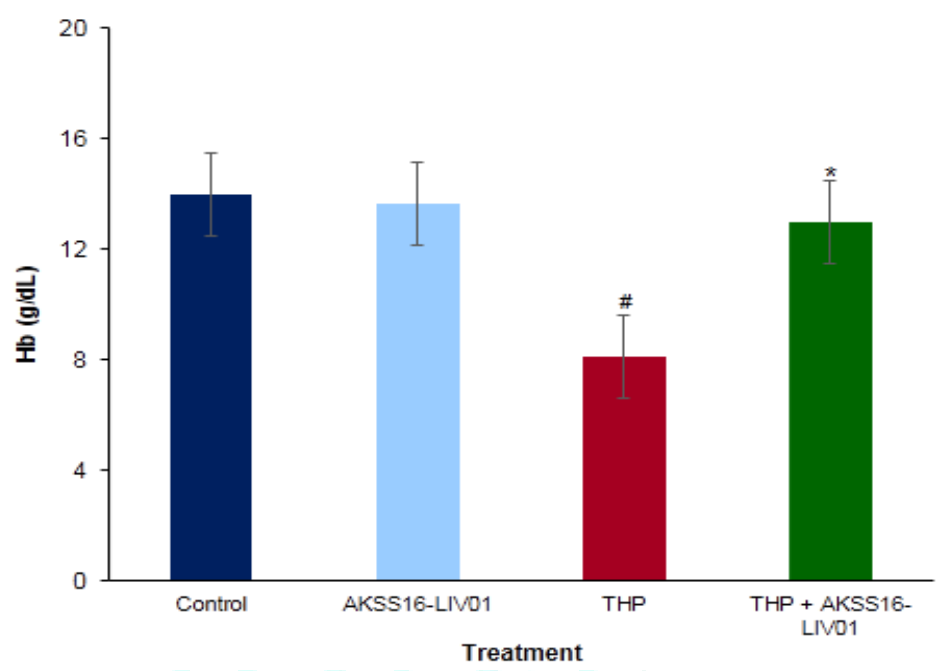

Figure 1: Effect of multi herbal formulation (AKSS16-LIV01) on haemoglobin (Hb) in mice. All data were expressed as means \pm $\mathrm{SE}(\mathrm{n}=6$ /group). \#significantly different from the control group at $\mathrm{p}<0.001$ and *significantly different from (THP) group values at $\mathrm{p}<0.001$. Data comparison was performed using one way ANOVA followed by Tukey's Multiple Comparison Test.

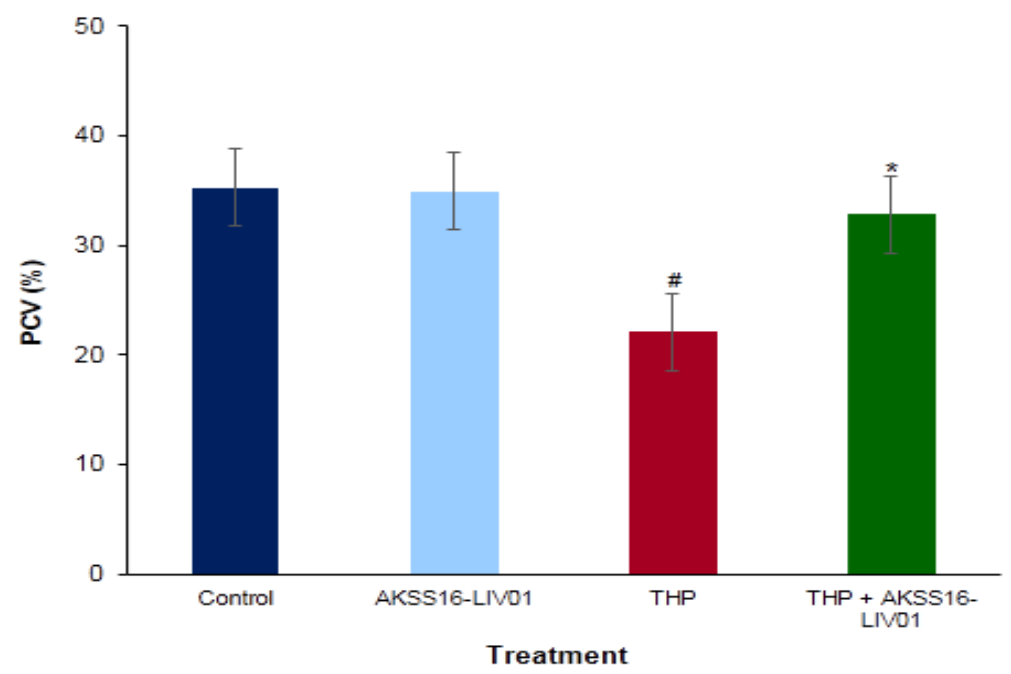

Figure 2: Effect of multi herbal formulation (AKSS16-LIV01) on packed cell volume (PCV) in mice. All data were expressed as means \pm SE (n=6/group). "significantly different from the control group at $\mathrm{p}<0.001$ and *significantly different from (THP) group values at $\mathrm{p}<0.001$. Data comparison was performed using one way ANOVA followed by Tukey's Multiple Comparison Test. 


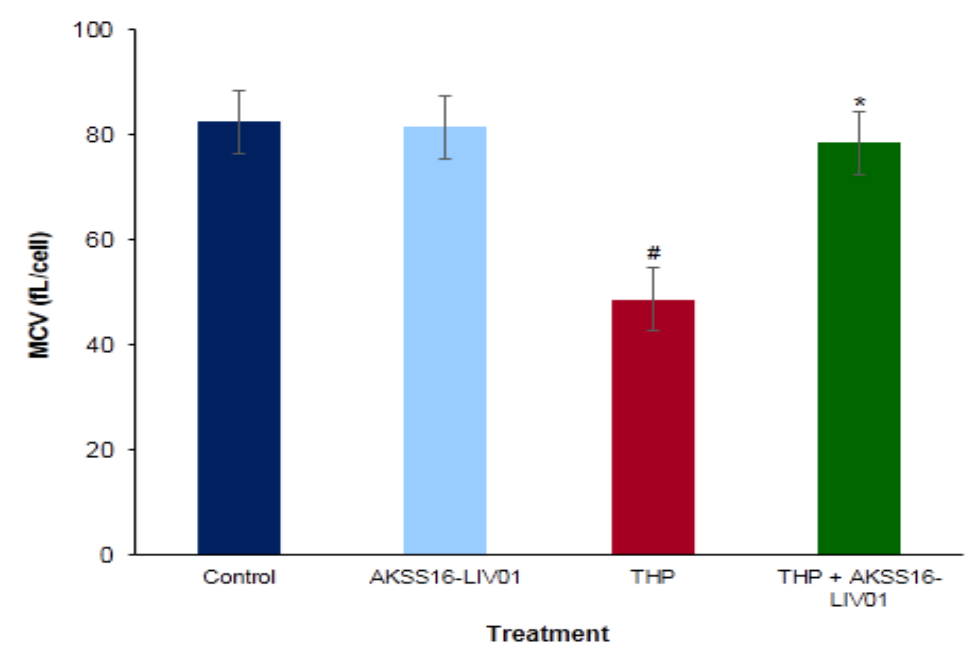

Figure 3: Effect of multi herbal formulation (AKSS16-LIV01) on mean cell volume (MCV) in mice. All data were expressed as means \pm SE ( $n=6 /$ group). "significantly different from the control group at $\mathrm{p}<0.001$ and *significantly different from (THP) group values at $\mathrm{p}<0.001$. Data comparison was performed using one way ANOVA followed by Tukey's Multiple Comparison Test.

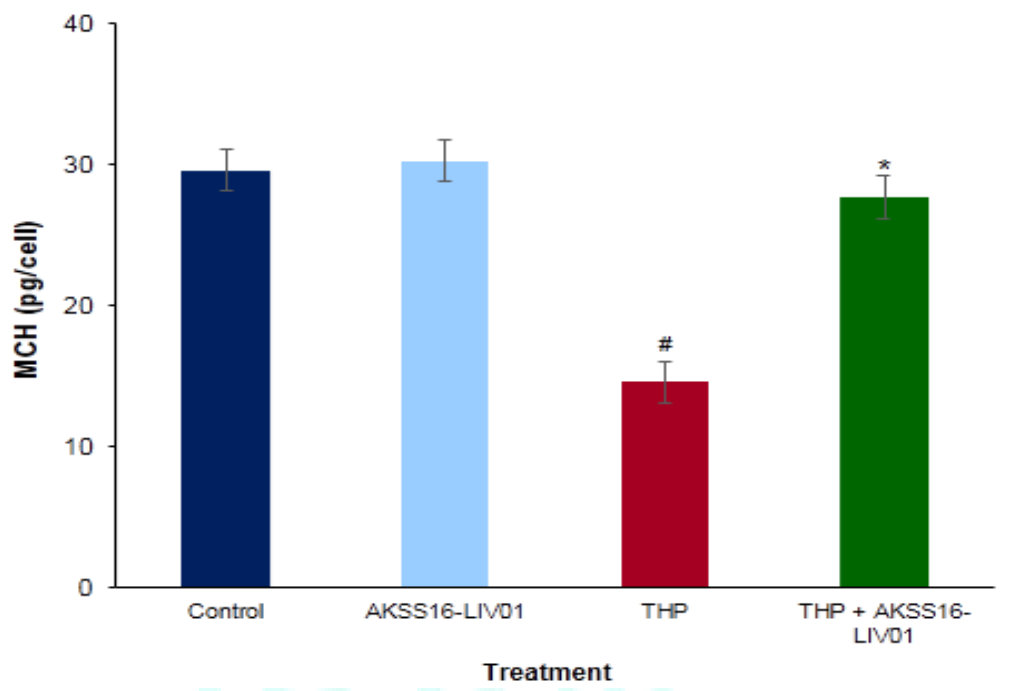

Figure 4: Effect of multi herbal formulation (AKSS16-LIV01) on mean cell hemoglobin (MCH) in mice. All data were expressed as means \pm SE ( $n=6 /$ group). \#significantly different from the control group at $\mathrm{p}<0.001$ and *significantly different from (THP) group values at $\mathrm{p}<0.001$. Data comparison was performed using one way ANOVA followed by Tukey's Multiple Comparison Test.

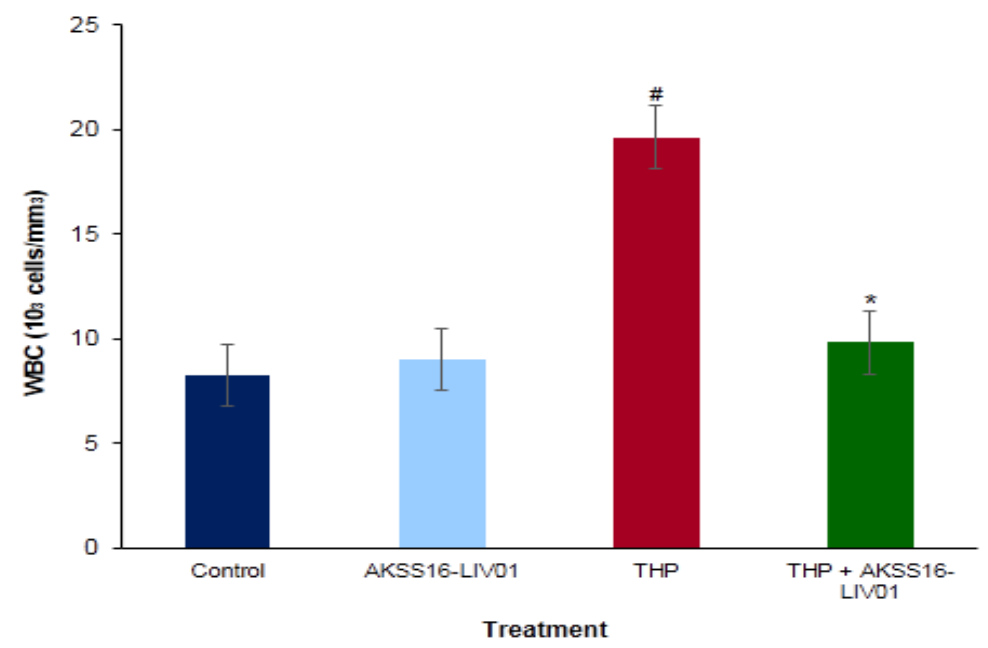

Figure 5: Effect of multi herbal formulation (AKSS16-LIV01) on white blood cell (WBC) in mice. All data were expressed as means \pm SE ( $n=6 /$ group). "significantly different from the control group at $p<0.001$ and *Significantly different from (THP) group values at $\mathrm{p}<0.001$. Data comparison was performed using one way ANOVA followed by Tukey's Multiple Comparison Test. 


\section{DISCUSSION}

Analgesics as fixed dose combination are very useful for fast pain relief. Tramadol hydrochloride/paracetamol (THP) is a fixed dose combination consists of two analgesics tramadol and paracetamol used for treats moderate to severe pain 15 . It is well established that overdose or chronic use of analgesics specially fixed dosses form developed mild to severe adverse effects and sometimes damage various organs like liver, kidney and brain ${ }^{16}$. In very recent study confirm that administration of THP upon animal model severely disturbed hematological and biochemical parameters 17. To prevent these deleterious effects we simultaneously administered our newly developed multi herbal formulation (AKSS1-LIV01) in mice. It is reported that treated with THP at a dose of $1.68 \mathrm{~g} / 300 \mathrm{ml}$ of water on mice reduced the haemoglobin $(\mathrm{Hb})$, packed cell volume (PCV), and mean corpuscular volume (MCV) values. Another report depict that lower haemoglobin $(\mathrm{Hb})$ value leads to iron deficiency anaemia which is characterized by a microcytic hypochromic blood picture. In the present study our result also confirm that administration of THP (1.68 $\mathrm{g} / 300 \mathrm{ml}$ of water) decline $\mathrm{Hb}, \mathrm{PCV}, \mathrm{MCH}$ and MCV values could be attributed to disturbed hematopoiesis, destruction of erythrocytes. The low PCV and Hb concentration and the abnormally low values of MCV and MCH are indications of microcytic anaemia. Medicinal plants enrich with various compounds capable to control and maintained the various blood parameters. Pre-treatment with newly developed multi herbal formulation (AKSS16-LIV01) along with THP elevate $\mathrm{Hb}, \mathrm{PCV}, \mathrm{MCH}$ and $\mathrm{MCV}$ values may indirectly protect the body from the anaemia.

Elevated aspartate transaminase (AST) and alanine transaminase (ALT) levels are strong indicators of inflammatory conditions and injury to the liver, while increased white blood cells (WBC) level is generally recognized as an inflammatory response 18,19 . Inflammatory conditions may induce malnutrition in the body ${ }^{20}$. It is reported that inflammatory conditions can interfere with the body's ability to use stored iron and absorb iron from the $\operatorname{diet}^{21}$. Our result clearly showed that treatment with THP abruptly increased serum aspartate transaminase (AST) and alanine transaminase (ALT) levels as well as elevate white blood cells (WBC) count indicate THP produce inflammatory response and affects liver cell, disturbed homeostasis. On the other hand administration with newly developed multi herbal formulation (AKSS16-LIV01) along with THP decline the AST, ALT value and WBC count protect the liver against THP induced inflammation. Thus our developed multi herbal formulation composed with six medicinal plants and three medicinal spices may be able to protect haematological disturbance caused by THP.

\section{CONCLUSION}

This investigation shows that multi herbal formulation (AKSS16-LIV01) has the ability to protect the haematopoietic cells from the damaging effects of exposure to Tramadol hydrochloride/paracetamol (THP) and this protection might be attributed to the anti-oxidative power of multi herbal formulation (AKSS16-LIV01). Thus, we believe that the developed formulation composed of medicinal herbs and medicinal spices might be a therapeutic medicine in future for the prevention of haematological dysfunction.

\section{Acknowledgement}

The authors are thankful to Prof. S K Pal, Senior Professor Department of Chemical, Biological \& Macromolecular Sciences S N Bose National Centre for Basic Sciences JD
Block, Sector III Salt Lake City for his guidance and valuable suggestion during this investigation.

\section{Authors' Contribution}

Soumendra Darbar and Atiskumar Chattapadhyay conceived and designed the experiment. Soumendra Darbar and Srimoyee Saha conducted the animal and biochemical experiments. Soumendra Darbar , Atiskumar Chattapadhyay and Kaushikisankar Pramanik wrote and revised the manuscript.

\section{Conflicts of Interest}

All authors report no conflicts of interest regarding this manuscript.

\section{Authors' Funding}

No funding support for this current work.

\section{REFERENCES}

1. Food U, Administration D: Fda Warns About Several Safety Issues With Opioid Pain Medicines; Requires Label Changes. Fda Drug Safety Communication. In.; 2016.

2. Mitrašinović-Brulić M, Kulovac A, Suljević D: Chronic Effects Of Tramadol Hydrochloride/Paracetamol Oral Administration On Haematological Parameters And Glucose Level In Wistar Rats.

3. Leppert W: Tramadol As An Analgesic For Mild To Moderate Cancer Pain. Pharmacological Reports 2009; 61(6):978-992.

4. Yanarates O, Dogrul A, Yildirim V, Sahin A, Sizlan A, Seyrek M, Akgül Ö, Kozak O, Kurt E, Aypar U: Spinal 5-Ht7 Receptors Play An Important Role In The Antinociceptive And Antihyperalgesic Effects Of Tramadol And Its Metabolite, O-Desmethyltramadol, Via Activation Of Descending Serotonergic Pathways. Anesthesiology: The Journal Of The American Society of Anesthesiologists 2010; 112(3):696-710.

5. Kaneko K, Umehara M, Homan T, Okamoto K, Oka M, Oyama T: The Analgesic Effect Of Tramadol In Animal Models Of Neuropathic Pain And Fibromyalgia. Neuroscience Letters 2014; 562:28-33.

6. Aldiwan Ma, Alzobidy Amh, Younis Ma: The Effect Of Tramadol On Some Blood And Biochemical Parameters Of Male Rats (Rattus Norvegicus). Baghdad Science Journal 2015; 12(3):496502.

7. Clack L, Kadlec L, Wendicke A: Producing Better Data To Help Combat Opioid Dependence. Journal of Ahima 1918:39.

8. Chandanwale As, Sundar S, Latchoumibady K, Biswas S, Gabhane M, Naik M, Patel K: Efficacy And Safety Profile Of Combination Of Tramadol-Diclofenac Versus TramadolParacetamol In Patients With Acute Musculoskeletal Conditions, Postoperative Pain, And Acute Flare Of Osteoarthritis And Rheumatoid Arthritis: A Phase Iii, 5-Day Open-Label Study. Journal Of Pain Research 2014; 7:455.

9. Raffa Rb, Clark-Vetri R, Tallarida Rj, Wertheimer Ai: Combination Strategies For Pain Management. Expert Opinion On Pharmacotherapy 2003; 4(10):1697-1708.

10. Hasan Sz, Misra V, Singh S, Arora G, Sharma S, Sharma S: Current Status Of Herbal Drugs And Their Future Perspectives. In: Biol Forum Int J: 2009. Citeseer: 12-17.

11. Srivastava S, Lal Vk, Pant Kk: Polyherbal Formulations Based On Indian Medicinal Plants As Antidiabetic Phytotherapeutics. Phytopharmacology 2012; 2(1):1-15.

12. Thyagarajan $S$, Jayaram S, Gopalakrishnan V, Hari R, Jeyakumar P, Sripathi M: Herbal Medicines For Liver Diseases In India. Journal Of Gastroenterology And Hepatology 2002; 17:S370S376.

13. Darbar S, Saha S, Pramanik K, Chattopadhyay A: Preliminary Assessment Of Acute And 28-Day Repeated Dose Oral Toxicity Of A Newly Developed Herbal Mixture On Experimental Animal. Indian Journal Of Pharmaceutical Education And Research 2020; 54(1):135-142.

14. Adhikari A, Darbar S, Chatterjee T, Das M, Polley N, Bhattacharyya M, Bhattacharya S, Pal D, Pal Sk: Spectroscopic Studies On Dual Role Of Natural Flavonoids In Detoxification of Lead Poisoning: Bench-To-Bedside Preclinical Trial. Acs Omega 2018; 3(11):15975-15987. 
15. Thornton J, Losowsky M: Severe Thrombocytopenia After Paracetamol Overdose. Gut 1990; 31(10):1159.

16. Waris N, Kausar R, Waris N, Naz F, Raza A: Effect Of Extra Panadol On Blood And Behavior Of Rats. J Bioanal Biomed 2017; 9(4):206-211.

17. Cascio Mj, Deloughery Tg: Anemia: Evaluation And Diagnostic Tests. Medical Clinics 2017; 101(2):263-284.

18. Tung H-T, Cook F, Wyatt R, Hamilton P: The Anemia Caused By Aflatoxin. Poultry Science 1975; 54(6):1962-1969.
19. Thapa B, Walia A: Liver Function Tests And Their Interpretation. The Indian Journal Of Pediatrics 2007; 74(7):663671.

20. Gonzalez-Casas R, Jones Ea, Moreno-Otero R: Spectrum Of Anemia Associated With Chronic Liver Disease. World Journal of Gastroenterology: Wjg 2009; 15(37):4653.

21. Gkamprela E, Deutsch M, Pectasides D: Iron Deficiency Anemia In Chronic Liver Disease: Etiopathogenesis, Diagnosis And Treatment. Annals Of Gastroenterology 2017; 30(4):405. 